\title{
18. THE CAUSE OF THE BOTTOM-SIMULATING REFLECTION IN THE VICINITY OF THE CHILE TRIPLE JUNCTION ${ }^{1}$
}

\author{
Nathan L.B. Bangs, ${ }^{2}$ Dale S. Sawyer, ${ }^{3}$ and Xenia Golovchenko ${ }^{4}$
}

\begin{abstract}
Leg 141 drilling in the vicinity of the Chile triple junction has, for the first time, logged the interval at the base of the gas hydrate layer where the bottom-simulating reflection (BSR) is generated, to reveal the nature of the impedance contrast producing the BSR. The concentration of hydrate is estimated from geophysical logs recorded at Site 859 by the increase in $P$-wave velocity $\left(V_{p}\right)$ of the hydrate-bearing intervals. Hydrate occupies no more than $18 \%$ of the pore space and is not concentrated enough to produce bright reflections. The BSR is believed to be produced by a sharp drop in $V_{p}$, and presumably density, from about $1.95 \mathrm{~km} / \mathrm{s}$ to 1.6 $\mathrm{km} / \mathrm{s}$ within an $8 \mathrm{~m}$ interval. A synthetic seismogram constructed from the Site $859 \log$ data produces a seismic reflection that is similar both in amplitude and waveform to that observed on the seismic line intersecting the drill site. Near-incidence models of the BSR in the vicinity of Site 860 show that a low-velocity layer with similar thickness $(12 \mathrm{~m})$ reproduces the BSR at this location. Modeling of the amplitude-versus-offset (AVO) of the BSR at Site 860 indicates that the low $V_{p}$ interval that produces the BSR does not show a corresponding drop in shear-wave velocity. This corresponds to properties that are expected if small quantities of free gas $(\sim 1 \%)$ are present in the interval. Some of the gas may be produced by dissociation along the base of the hydrate caused by shifting of the hydrate stability field because of increasing temperatures and tectonic uplift as the Chile seafloor spreading center is subducted beneath the Chile margin.
\end{abstract}

\section{INTRODUCTION}

Gas hydrates are solids constructed mainly of water that contain large quantities of gas, predominantly methane (Kvenvolden and Barnard, 1983), within their crystalline lattice. They form commonly in marine sediments off continental margins and have morphologies that are believed to vary from massive solids several meters thick to disseminated crystals that form in sediment pore spaces (Sloan, 1990). In water depths greater than about $500 \mathrm{~m}$, pressure and temperature conditions from the seafloor to as much as $1100 \mathrm{~m}$ below it meet the conditions for hydrate formation (Kvenvolden and McMenamin, 1980). Because of the rise in temperature with depth below the seafloor, hydrates dissociate below depths of usually a few hundred meters depending on water depths and local thermal gradients.

Commonly associated with hydrates are strong seismic reflections known as bottom simulating reflections (BSR) that lie within the shallow sections of continental margins. Since the 1960s BSRs have been identified in seismic sections, primarily in accretionary complexes along convergent margins and in passive margin settings (Markl et al., 1970; Shipley et al., 1979; Kvenvolden and Barnard, 1983; Hyndman and Davis, 1992). The coincidence of the theoretical base of the hydrate stability zone and the strong, phase-reversed BSRs that intersect pre-existing sedimentary structures and roughly parallel the seafloor have led researchers to identify hydrates in seismic sections by association with the BSR (Tucholke et al., 1977; Shipley et al., 1979; Macleod, 1982). However, the association between gas hydrates and the BSR is currently mainly circumstantial. There have been no data to reveal the cause of the BSR because of a reluctance to penetrate the BSR and risk releasing free gas potentially trapped beneath the hydrate. Leg 141 drilled the accretionary complex offshore of southern Chile, and for the first time a BSR beneath gas hydrate was penetrated to conduct a geophysical examination of the base of the hydrate inter-

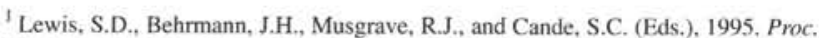
$O D P_{2}$ Sci. Results, 14I: College Station, TX (Ocean Drilling Program),

${ }^{2}$ Institute for Geophysics, University of Texas at Austin, 8701 Mopac Expressway, Austin, TX 78759-8397, U.S.A.

${ }^{3}$ Department of Geology and Geophysics, Rice University, P.O. Box 1892, Houston. TX 77251, U.S.A.

${ }^{4}$ Lamont-Doherty Earth Observatory, Columbia University, Palisades, NY 10964,
}

val. The purpose of this paper is to use Leg 141 geophysical logs and the seismic data from Line 745 to examine the cause of the BSR and its genetic relation to the gas hydrate.

BSRs are believed to be produced in one of two ways. A strong, phased-reversed BSR could be produced by accumulation of free gas at the base of the hydrate layer. By analogy to seismic "bright spots" that are characteristic of gas accumulations within structural traps, the BSR may be produced by the drop in acoustic impedance associated with free gas accumulating in sediment pore space beneath the hydrate. An analysis of the BSR waveform offshore of Peru has attributed the BSR to free gas accumulated at the base of the hydrate-bearing sediments (Miller et al., 1991). The brightness of the reflection offshore of Peru is caused by the large impedance contrast at the top and bottom of a 5-m to 17-m-thick layer containing free gas (Miller et al., 1991). The gas accumulation implies that hydrates may reduce permeability and act as a trap, as has long been suspected (Bryan, 1974; Kvenvolden and Barnard, 1983; Dillon and Paull, 1983). Gas has been inferred at the base of the hydrate from the analysis of "bright spots" (White, 1979; Collins and Watkins, 1985), and commercial gas production has recovered gas from the base of the hydrate layer since 1973 at the Mesoyakha gas hydrate field in Russia (Sloan, 1990).

Hydrate greatly alters the acoustic properties of sediments, and the BSR may be produced simply by the large contrast in properties of hydrate-bearing and hydrate-free sediments at the base of the hydrate layer (Stoll and Bryan, 1979; Macleod, 1982; Hyndman and Spence, 1992). The seismic velocity of the hydrate is considerably greater than the velocity of the pore fluids and unconsolidated sediments that it displaces $(\sim 3.8 \mathrm{~km} / \mathrm{s}$ for hydrate vs. $1.5-1.9 \mathrm{~km} / \mathrm{s}$ for fluid saturated sediment) (Whalley, 1980; Hamilton, 1978). Furthermore, hydrate-bearing sediments are likely to increase velocity by cementing sediment grains, and velocities as high as $4.7-5.9 \mathrm{~km} / \mathrm{s}$ have been measured (Pearson et al., 1986). Where massive hydrates were cored offshore of Guatemala on Leg 84 , logging showed a 15 -m-thick interval with velocities as high as $3.6 \mathrm{~km} / \mathrm{s}$ (Mathews and von Huene, 1985). Along the Cascadia margin, hydrate at the base of the stability field is believed to be concentrated to greater than $30 \%$ of the pore space. The large difference in impedance between sediments with $30 \%$ hydrate in the pore space and sediments with no hydrate below the hydrate stability zone produces the BSR, and it is not believed to be generated by free gas (Hyndman and Davis, 1992). 


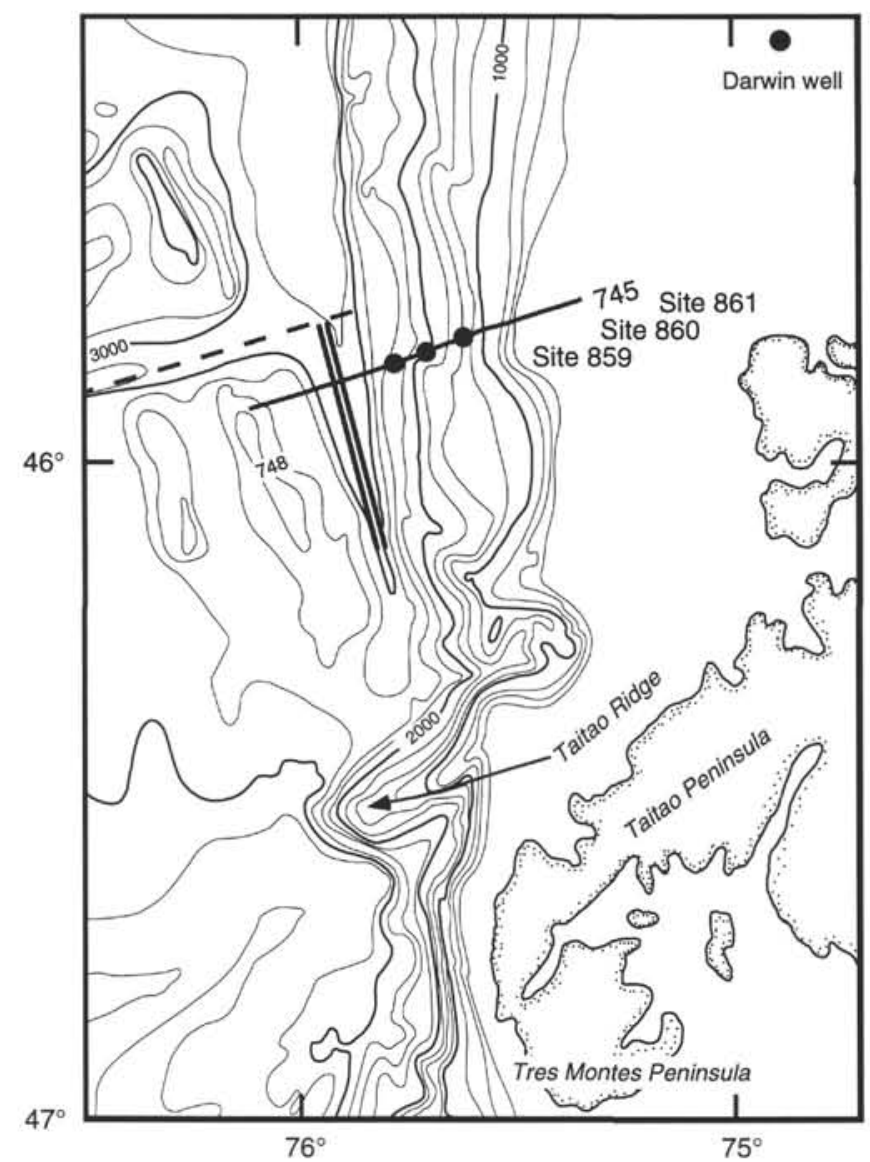

Figure 1. Bathymetric map of the Chile triple junction showing the locations of three Leg 141 drill sites that form a transect across the Chile margin slope. The double lines lie along the Chile seafloor spreading ridge. The dashed line marks the Darwin fracture zone. Intersecting the drill sites is seismic Line 745 acquired as part of the site survey for drilling on Conrad cruise RC2901.

DSDP and ODP drilling has recovered samples in the hydrate interval to depths just above the BSR. Hydrates have been recovered offshore of Peru (Kvenvolden and Kastner, 1990), from the MiddleAmerican trench off Mexico (Shipley and Didyk, 1982), Guatemala (Mathews and von Huene, 1985), and the Blake Outer Ridge (Sheridan et al., 1982), and other locations. But, drilling prior to Leg 141 did not penetrated the base of the gas hydrate to reveal the properties that cause the BSR. Leg 146 has now also penetrated and logged the BSR (McKay et al., 1994).

In this paper we examine the physical properties using Leg 141 $\log$ data to determine the cause of the BSR. Sonic $P$-wave velocities are used to estimate the concentration of hydrate above the BSR, and if any, the quantity of free gas beneath the gas hydrate. The physical properties from Site 859 are also used to construct a synthetic seismogram that is compared to the seismic reflection data to establish the relationship between the physical properties in the log and the seismic response of the BSR. Seismic modeling is also used to examine the amplitude-versus-offset (AVO) response of the BSR to compare the seismic data to models that represent free gas and no free gas cases.

\section{TECTONIC SETTING}

The Chile margin near the Chile triple junction is an unusual tectonic setting that is currently disturbing the pressure and temperature conditions within the sediments where hydrates have formed. North of the triple junction, the Chile margin lies along the collisional boundary between the South American continental plate and the
Nazca Plate. The Nazca Plate is subducting beneath the Chile margin along the Chile trench at a rate of about $80 \mathrm{~km} / \mathrm{m}$.y. Seismic Line 745 lies just north of the present-day triple junction, and the Chile seafloor spreading ridge lies approximately $5 \mathrm{~km}$ from the margin. The spreading center is expected to be subducted in approximately $100,000 \mathrm{yr}$. High heat flow associated with the spreading ridge has greatly elevated thermal gradients near the ridge (Behrmann, Lewis, Musgrave, et al., 1992; Bangs and Brown, this volume).

The main structural elements of the margin result from plate convergence (Bangs et al., 1992). Hydrate forms primarily in a small accretionary complex approximately $8-10 \mathrm{~km}$ wide. The accretionary complex extends from the trench to a prominent slope break and is characterized by chaotic structures resulting from extensive tectonism. A 5-km-wide syncline of gently folded sediments lies within a small forearc basin immediately landward of the accretionary complex that is probably underlain by the seaward extent of continental basement. Much of the toe of the slope is currently undergoing uplift with advancement of the subducting ridge (Behrmann, Lewis, Musgrave, et al., 1992).

\section{GEOPHYSICAL DATA}

\section{Drilling Data}

Geophysical logs through the BSR were acquired only at Site 859 on Leg 141 (Fig. 1). Logging attempts at Site 860 failed due to poor hole stability, and Site 861 was not logged. The only data discussed in this presentation are from Site 859.

While logging Site 859 we encountered problems from hole conditions that degraded the quality of some logs. The hole diameter was washed out to sizes exceeding the maximum range of the caliper, 43 $\mathrm{cm}$, for much of the interval from 70 to $225 \mathrm{mbsf}$. The density log, which is particularly sensitive to hole diameter, is clearly affected. The sonic and resistivity data are reasonably consistent despite the hole conditions, and are the focus of our interpretation.

\section{Seismic Data}

The seismic data were acquired on R.V. Conrad cruise RC2901 as part of the site survey for drilling. The seismic source consisted of a 10-gun array, tuned to suppress the bubble pulse, with a total volume of 3743 in. $^{3}(61.3 \mathrm{l})$. Shots were fired at $20 \mathrm{~s}$ intervals, producing a shot spacing of approximately $50 \mathrm{~m}$, and received on a $3-\mathrm{km}$-long, 240-channel digital streamer with 12.5 -m groups.

\section{The BSR}

The BSR was drilled at three sites (859-861) along seismic Line 745 (Fig. 2). Early Pliocene to late Pleistocene silty clay and clayey silts at Site 859 grade upslope into coarser debris-flow silts, sands, and gravels of the same ages in the vicinity of Site 861. Site 861 on the upper slope intersects the BSR, where it is a weak reflection at about 250 mbsf. Site 861 lies at the landward terminus of the BSR, and the reflection decreases in amplitude until lost within the other seismic events in lower shelf sediments just landward of Site 861. Site 860 lies at the seaward edge of a forearc basin near the seaward extent of the continental crust. At this site the BSR lies at approximately 200 mbsf and is a particularly strong reflection. It is stronger in amplitude than the forearc basin strata it intersects, and is reasonably uniform in amplitude across the forearc basin. The BSR is semi-continuous across the lower slope to the seaward termination of the BSR at Site 859 . Some local variations in brightness probably reflect focusing effects from rough seafloor topography along the lower slope. At Site 859 the BSR is easily recognized as the strongest reflection below the seafloor and lies at approximately $100 \mathrm{mbsf}$. The large variation in the depth of the BSR is caused by lateral differences in thermal gradient (Cande et al., 1987). High thermal gradients develop at the toe of the lower slope due to the proximity of hot, zero-age crust of the subducting spreading ridge. 


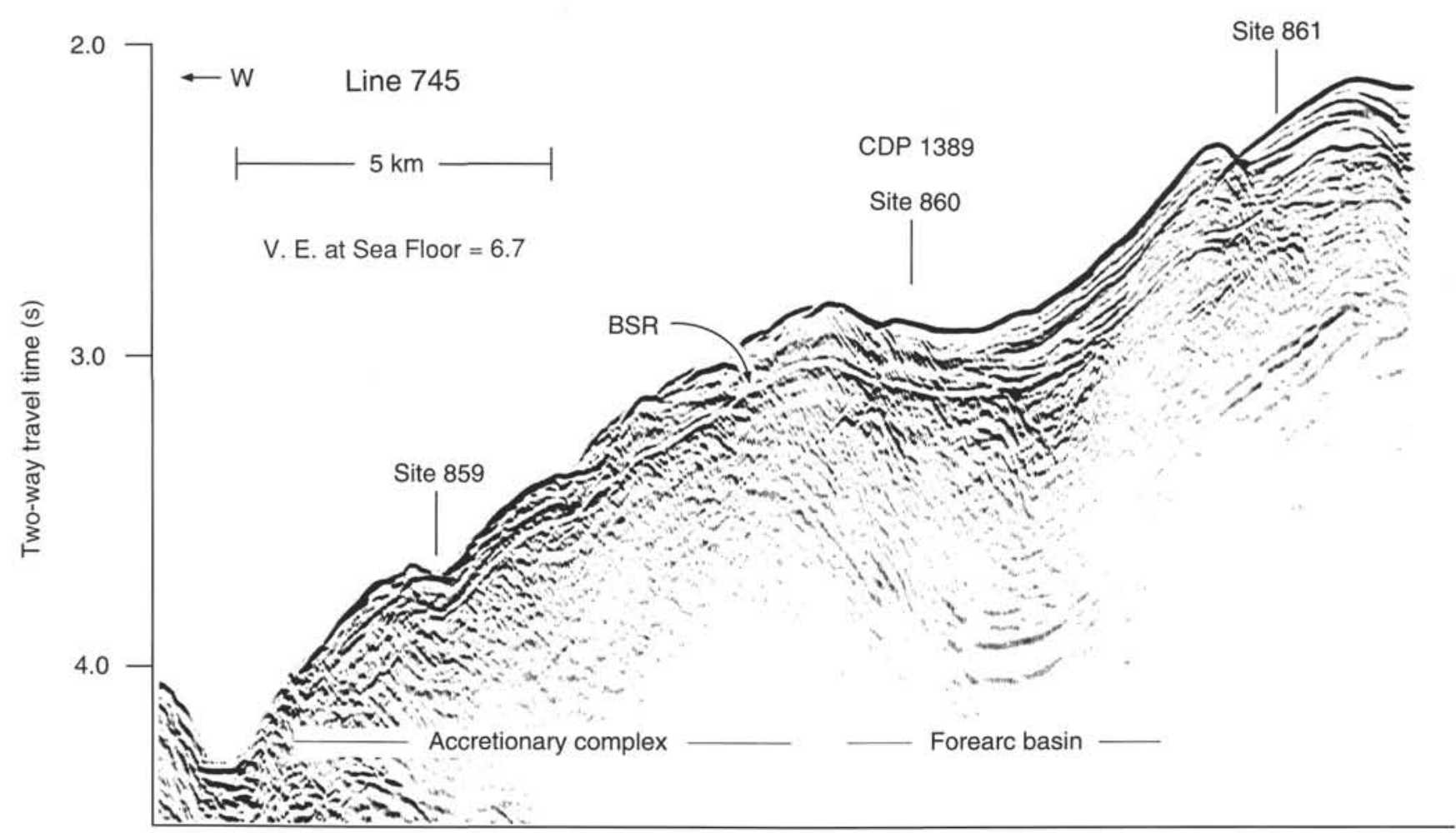

Figure 2. A migrated version of Line 745 showing the BSR at about $0.2 \mathrm{~s}$ below seafloor. No time varying gain is applied to allow comparison of the relative amplitudes of the BSR and other reflections. The BSR is a bright reflector where it was drilled at Site 859 and 860.

\section{RESULTS}

\section{Logging Results}

Two intervals above the BSR indicate the presence of hydrates in the pore spaces as described in Behrmann, Lewis, Musgrave, et al. (1992) (Fig. 3). In Layer A (Fig. 3) the velocity and resistivity are higher than those of the underlying Layer C. An increase in velocity from about 1.85 to $1.90 \mathrm{~km} / \mathrm{s}$ is attributed mainly to the addition of hydrates. Although some of this change could be due to compaction, resistivity also shows a corresponding increase. Resistivity is sensitive to the presence of hydrates, which can increase resistivities several orders of magnitude depending on temperatures of the sediments and pore-fluid salinity (Pearson et al., 1986). Distinct chloride and salinity anomalies observed within Interval A indicate a component of freshening from hydrate melting of about $5 \%-15 \%$ (Behrmann, Lewis, Musgrave, et al., 1992). The largest anomalies in pore-fluid chemistry were found at $35 \mathrm{mbsf}$, above the logged interval, and indicate as much as $25 \%$ freshening.

Layer C is a low-velocity and low-resistivity interval interpreted to indicate a decrease in hydrate concentration to nearly zero. The chlorinity and salinity of interstitial fluids indicated no freshening effect within the 70-88-mbsf interval. These are the lowest logged velocities above the BSR, and based on the pore fluid chemistry, we believe these velocities indicate the velocity of the hydrate-free sediments near the base of the hydrate stability field.

A second hydrate layer (D) is indicated in the logs between 88 to $97 \mathrm{mbsf}$. Velocities of $1.95 \mathrm{~km} / \mathrm{s}$ are the highest within the hydrate stability zone, and have a corresponding high resistivity. This interval probably also has a higher velocity because of an increased concentration of hydrate, but because this thin interval may have been missed by pore-fluid sampling no chemical anomaly is observed to confirm this. The interval may also begin below $90 \mathrm{mbsf}$, because a fluid sample at 90 mbsf has no chemical anomaly.
The BSR itself is believed to be produced from the top and bottom interfaces of Interval E. The log shows a large low-velocity anomaly in Interval E, with velocities decreasing to an average of $1.6 \mathrm{~km} / \mathrm{s}$, that is similar to the thin, low-velocity layer modeled by Miller et al. (1991) offshore of Peru. Extremely low values of $1.2 \mathrm{~km} / \mathrm{s}$ were recorded in Interval E. Each of the four traveltimes recorded between the source and receiver pairs, which are used to calculate the sonic logs, indicate low velocities in E; however, their responses are not consistent. The inconsistency causes the extreme apparent values of $1.2 \mathrm{~km} / \mathrm{s}$. We speculate that a weak signal, perhaps from poor sound transmission in this interval, results in inaccurate arrival identification by the instrument, or the inconsistencies are due to differences in ray paths between the source and receiver pairs, possibly from varying gas concentrations within Interval E. Below E, velocities increase to values similar to those above it. Resistivities are observed to increase slightly in the low-velocity interval. On the basis of these data we believe that the BSR is caused by a 7-m low-velocity layer similar to the free-gas layer model of Miller et al. (1991).

We can estimate hydrate concentration within Intervals A and D by the hydrates' effect on velocity, similar to Miller et al. (1991) and Hyndman and Spence (1992), using the time average equation of Wylie et al. (1956) for a three-phase material. The time average equation may overestimate the velocity for water-saturated sediments (Worthington, 1975), but results will improve if an additional solid phase such as hydrate replaces the fluids. This method attributes the velocity of the hydrate-bearing sediments to velocities of the components in their proportion to the total volume. No consideration is made of any increase in the rigidity of the material caused by cementation of the grains from the hydrate. Consequently, it may overestimate the quantity of hydrate, but with the small concentrations inferred here, cementation effects are probably minimal.

From the pore-fluid chemistry we assume that Interval $\mathrm{C}$ is hydrate free and provides an estimate of the velocity of the hydrate-free sediment of no greater than $1.85 \mathrm{~km} / \mathrm{s}$. Figure 4 shows the velocity of the 


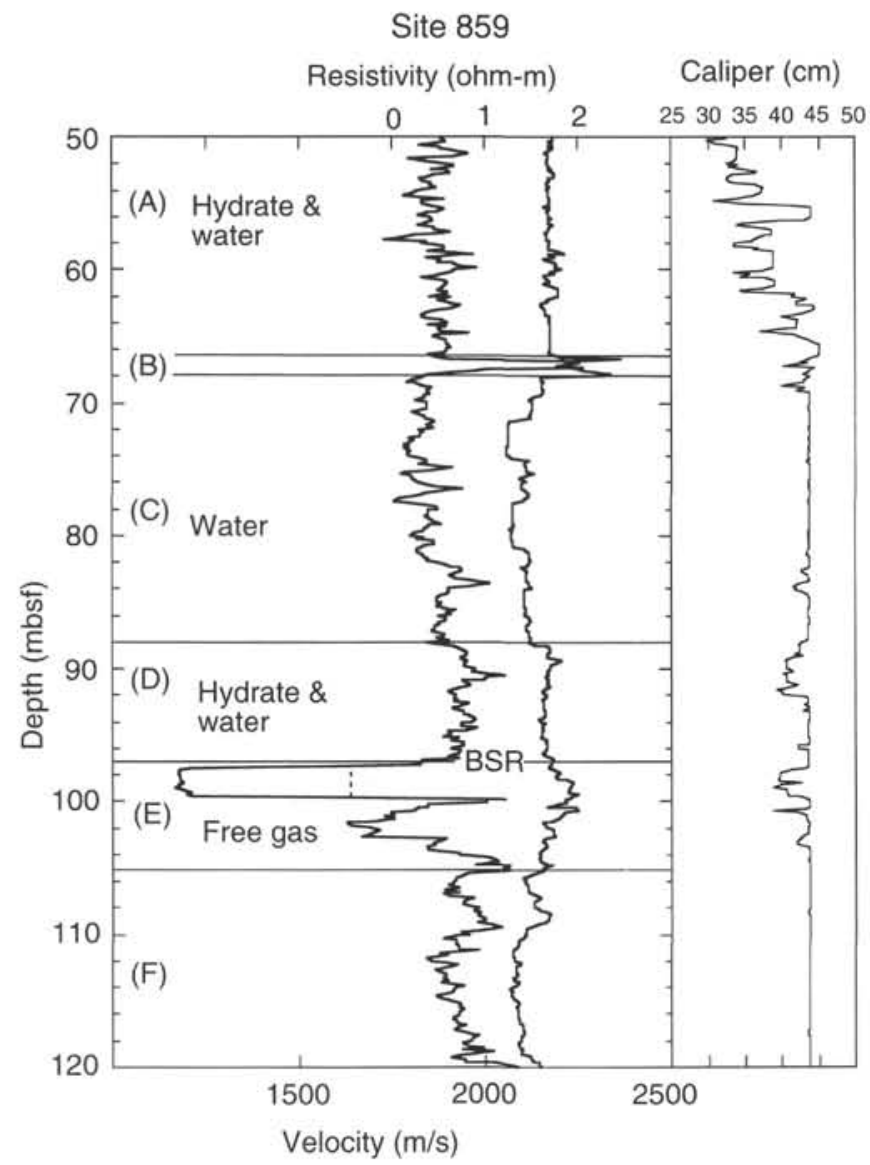

Figure 3. Sonic (left), resistivity (middle), and caliper (right) logs recorded at Site 859 through the hydrate interval and the BSR. Two hydrate-enriched intervals are noted, based on their relatively higher velocity and resistivity, and on the pore fluid geochemistry. The BSR is produced by low-velocity Layer E. The short dashed line shows the velocity for the upper $2 \mathrm{~m}$ of Layer $\mathrm{E}$ that was used in modeling. The velocities in the upper $2 \mathrm{~m}$ of Layer $\mathrm{E}$ are not believed to be as low as the log indicates. See text for more details.

sediment as a function of hydrate concentration based on the time average equation, assuming the interstitial fluid velocity is $1.5 \mathrm{~km} / \mathrm{s}$ and the hydrate velocity is $3.8 \mathrm{~km} / \mathrm{s}$. The $1.9 \mathrm{~km} / \mathrm{s}$ velocity in Layer A implies a hydrate concentration of about $10 \%$ of the pore space (pore space was measured to be $45 \%$ ), and $4.5 \%$ of the total rock volume. The velocities in Layer D of approximately $1.95 \mathrm{~km} / \mathrm{s}$ are the largest above the BSR and indicate the hydrate concentration is no greater than $18 \%$ of the pore space or $8 \%$ of the total rock volume.

Pore-fluid chemistry anomalies at Site 860 imply similar concentrations of hydrate to depths of $200 \mathrm{mbsf}$, but no logs are available to corroborate the existence of the hydrates there (Behrmann, Lewis, Musgrave, et al., 1992).

\section{The Synthetic Seismogram}

A large excursion to low velocities within narrow Interval $E$ is probably the cause of the acoustic impedance contrasts that produce the BSR. This structure resembles the character of physical properties predicted by Miller et al. (1991). We constructed a synthetic seismogram from the log data to relate the physical properties observed in the log at the BSR to its seismic response.

Reflection coefficients are calculated from an impedance log, the product of the sonic and density logs. The oversized hole at Site 859 made the density logs unreliable for calculating the impedance log. Rather than use a velocity-density relationship such as Hamilton

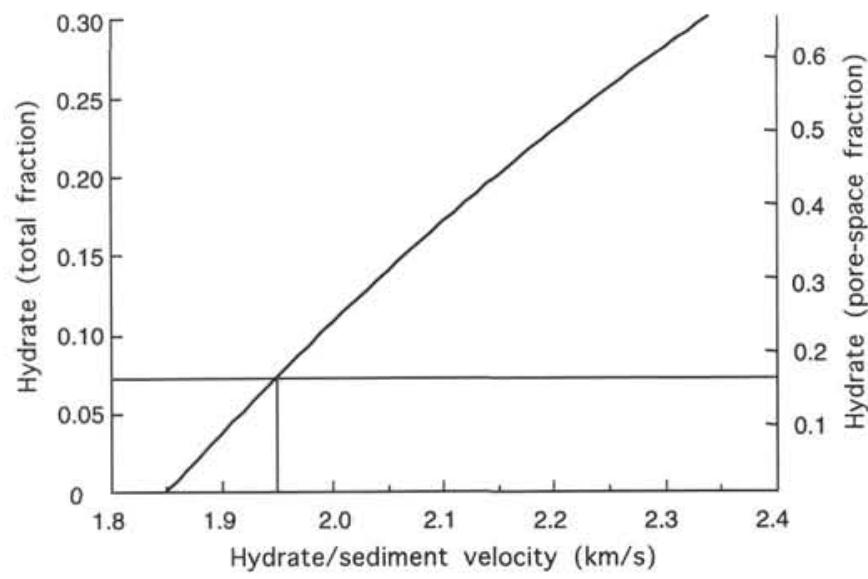

Figure 4. Estimates of the concentration of hydrate based on the increase in $P$-wave velocities as predicted from the time average equation of Wylie et al. (1956). We assume the hydrate-free sediment has a velocity of $1.85 \mathrm{~km} / \mathrm{s}$, the pore fluid $1.5 \mathrm{~km} / \mathrm{s}$, and the hydrate velocity is $4.0 \mathrm{~km} / \mathrm{s}$. The highest velocities within the hydrate stability field of $1.95 \mathrm{~km} / \mathrm{s}$, just above the BSR, imply a concentration of hydrate of $18 \%$ of the pore space.

(1978), which probably is not applicable for these unusually lowporosity sediments (Behrmann, Lewis, Musgrave, et al., 1992), we have chosen to use the available density information from the recovered cores. Figure 5 shows the densities with respect to the logged sonic velocities measured at the depths where the samples were taken. The solid line is a polynomial fit through these points that defines the relationship used to calculate density from velocity.

Sonic velocities and inferred densities converted to time and resampled to the sampling interval of the seismic data are shown in Figure 6. Seafloor properties were fixed to values measured in cores just below the seafloor and interpolated to the base of the drill pipe where log information begins. The very low values of $1.2 \mathrm{~km} / \mathrm{s}$ in the top $2 \mathrm{~m}$ of Layer E (Fig. 3) were eliminated, because waveforms produced without them are closer to what is observed. Structures less than $\sim 6 \mathrm{~m}$ thickness cannot be resolved with the $<60-\mathrm{Hz}$ bandwidth of the source. The normal incidence reflection coefficients shown in Figure 6 indicate 0.26 for the seafloor, which is expected in sediments of similar lithology (e.g., Shipley and Didyk, 1982), and compares well with estimates made directly from the seafloor and seafloor multiple using the methods of Warner (1990). This indicates that the seafloor reflection is reasonably well calibrated. The BSR is believed to be caused by the low velocities and densities that produce the -0.107 and 0.109 reflection coefficient pair just below $3.8 \mathrm{~s}$. These reflection coefficients compare well in magnitude with the -0.135 estimate for the BSR from the gas-layer model by Miller et al. (1991) and the -0.1 to -0.15 estimate of Hyndman and Spence (1992) for other BSRs. The transition from hydrate-free to hydrate-bearing intervals above the BSR produces only small impedance differences. The largest is at 88 mbsf $(3.79 \mathrm{~s})$, and this produces a reflection coefficient of only 0.025 .

The reflection series was convolved with a source wavelet derived from stacks of the seafloor reflection in the vicinity of Site 860 , to produce the synthetic seismogram (Fig. 6). The BSR waveform is characterized by a small positive (shaded) portion that is followed by a negative and positive pulse of nearly equal amplitude. The 0.01 -s separation and opposite sign of the reflection coefficient pair cause these events to interfere constructively to increase the amplitude of the reflection, making it greater than the two reflections independently. In the synthetic seismogram, the BSR amplitude is approximately $50 \%$ of the seafloor reflection amplitude, while the BSR reflection coefficients are $38 \%$ of the seafloor reflection coefficients. The BSR amplitude is enhanced because of constructive interference between the top and bottom of the interfaces of the layer, the "tuning effect" (Widess, 1973). 


\section{Comparison of the Synthetic Seismogram with the BSR}

The waveform of the synthetic seismogram is compared to the stacked seismic traces acquired in the vicinity of Site 859 in Figure 7. We assume that the stacked trace approximates a normal incidence response, and this assumption should be valid given the nearly constant amplitude at all offsets described below. In the seismic data, the BSR exhibits a small positive lobe preceding the nearly equal amplitude pair of negative and positive lobes seen in the synthetic seismogram. The events observed just above $4.0 \mathrm{~s}$ in the synthetic seismogram (Fig. 6) are produced from a prominent fault zone recognized in the cores at 230 mbsf, but they are weaker events in the seismic data than in the synthetic seismogram.

Unfortunately, Site 859 is located at a local seafloor syncline, and the waveform of both the seafloor and the BSR are locally distorted. This topography has produced the uneven seafloor reflection that complicates the comparison. There is no clearly defined seafloor reflection in the data for Site 859 , but the predicted timing of the seafloor and BSR events in the synthetic seismogram are not far off in any case. The local focusing has also increased the amplitude of the BSR at Site 859 and makes the amplitude comparison uncertain.

A better comparison of the waveforms and amplitudes can be made at Site 860 (Fig. 7). Site 860 is located in the small forearc basin and has a smooth seafloor, as is indicated by the lateral consistency of seafloor returns (Figs. 2 and 7). Although the BSR is considerably deeper at this location and the arrival times differ, the waveform and amplitude of the seafloor and BSR in the synthetic seismogram are reasonably well matched with those of the traces adjacent to Site 860 . The BSR wavelet is slightly longer in the data at this site, and as the modeling discussed below shows, the pulse can be better matched by increasing the thickness of the interval from $7 \mathrm{~m}$ in the synthetic seismogram to $12 \mathrm{~m}$. The sonic data indicate that a good possibility for the origin of the BSR is a thin layer of free gas below the hydrate.

\section{Amplitude vs. Offset of the BSR}

The sonic log data imply that the BSR is caused by a drop in velocity and density (i.e., impedance) in a thin layer, interpreted to be due to free gas at the base of the hydrate. Amplitude-versus-offset (AVO) of the BSR is examined to determine if free gas exists in the low-impedance interval. The effect free gas has on the AVO is examined below so that we can calculate models of the BSR for cases with and without free gas and compare these models to our seismic data.

AVO varies as reflection and transmission coefficients change with incidence angle, or offset, depending on Poisson's ratio in layers bounding the reflective interfaces (Shuey, 1985). Poisson's ratio is a function of the ratio of $V_{p}$ and shear-wave velocity $\left(V_{s}\right)$. Different fluid saturants within the pore space have a large effect on the physical properties of sediments such as $V_{p}$ and $V_{s}$ (and therefore Poisson's ratio), particularly when pore fluid is replaced by gas. The bulk modulus is greatly affected by a change from fluid to gas because of the increase in compressibility (Gassman, 1951). The result is a large drop in $V_{p}$ with increasing gas concentration up to a few percent free gas. Theoretical and laboratory studies predict that $80 \%-90 \%$ of the effect occurs with gas concentrations less than $2 \%-8 \%$ (Ostrander, 1984), depending on the strength of the sediment framework (Domenico, 1976, 1977; Gregory, 1976; Murphy, 1984). Greater consolidation and effective stress lead to a decrease in the sensitivity of $V_{p}$ to gas saturation. The presence of gas has a negligible effect on the shear modulus (Gassman, 1951), and consequently shear velocity is only affected by the density decrease with accumulation of gas in the pore space. This causes a slight increase in $V_{s}$ with gas concentration, but is negligible over the range of a few percent free gas. So the effect of a small accumulation of free gas in the pore space is a lower $V_{p}$ and constant $V_{s}$ which produce a drop in the $V_{p} / V_{s}$ ratio, and therefore a drop in Poisson's ratio. Shallow unconsolidated sediments have high

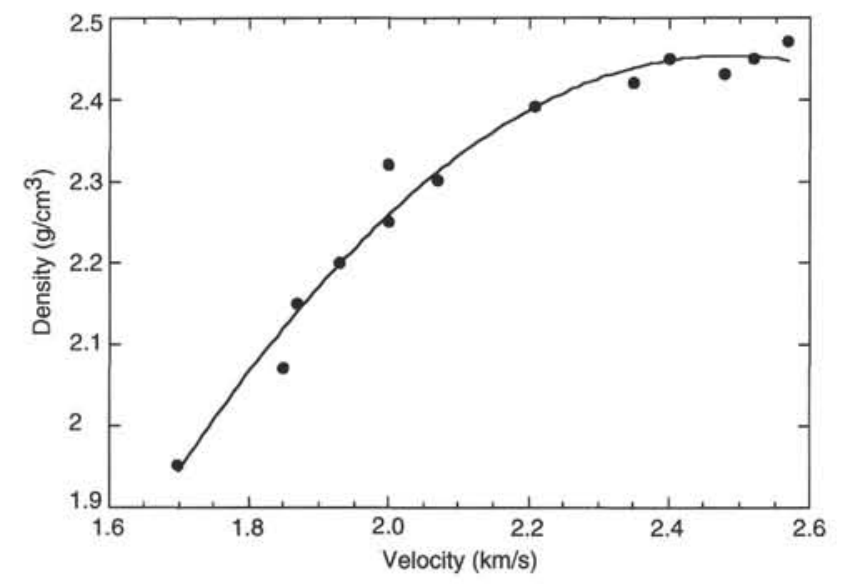

Figure 5. Densities measured in recovered core samples are plotted vs. sonic velocities from the corresponding cored intervals to establish a density-velocity relationship. The line is a polynomial fit to these points. This curve was used to calculate density from sonic velocities shown in Figure 6.

Poisson's ratios of usually close to 0.45 (Hamilton, 1979), while gas-saturated sands are as low as 0.1 (Domenico, 1976).

Theoretical estimates based on the Biot theory of sound propagation in sediments predict that in sediments with velocities similar to those near the BSR, $V_{p}$ will decrease to as low as $1.2 \mathrm{~km} / \mathrm{s}$ with as little as $2 \%$ free gas (Fig. 8A). Other estimates for higher velocity materials require larger concentrations of gas (Ostrander, 1984).

The seismic response from the low-impedance layer for the freegas case vs. no-free-gas case can be predicted from calculations of the reflection coefficients with incidence angle using the Zoeppritz equation (Shuey, 1985). Because the velocity in the BSR interval, is similar to that of Domenico (1976) we take Domenico's data as the best representation of the $V_{p}$ and $V_{s}$ response to gas for these sediments.

Two responses calculated for comparison of amplitudes with offset are shown in Figure 8B: one for the case where the $V_{p} / V_{s}$ ratio remains constant above, within, and below the low-velocity interval (i.e., no free gas in the low- $P$-wave-velocity interval), and a second case where $V_{p}$ and $V_{s}$ in the layer have values that correspond to a small quantity of free gas (1\%) as predicted by Domenico (1976; Fig. 8). The reflection coefficients are of opposite sign for the top and bottom interfaces of the layer. The BSR received at our farthest offset, $3.0 \mathrm{~km}$, has an incidence angle of $45^{\circ}$. In the case where $1 \%$ free gas is present in the low-impedance layer, reflection coefficients at incidence angles of $45^{\circ}$ are double those in the no-free-gas case. In the $1 \%$-free-gas case the amplitude is roughly constant from $0^{\circ}$ to $45^{\circ}$ incidence angle. For comparison, larger quantities of free gas (at least $2 \%$ free gas according to the Domenico data) produce larger AVO as predicted by Minshull and White (1989) and Hyndman and Spence (1992). The $2 \%$-free-gas case also has a reflection coefficient at normal incidence almost 2 times larger than with $1 \%$ free gas.

Full-fold common depth point (CDP) gathers in the vicinity of Site 860 , where the BSR is a strong reflection event, provide an example of its AVO behavior. Examination of AVO requires consideration of several factors. As discussed above, local seafloor topography and its focusing effects complicate accurate measurements of BSR reflection coefficients near Site 859. Rather than trying to model the effect of topography, we analyze CDP 1389 at Site 860 , where the seafloor is reasonably smooth and dips are less than $1.5^{\circ}$.

Synthetic seismograms assuming $1 \%$ free gas and no free gas in the low-impedance interval at CDP 1389 were constructed based on techniques of Chapman (1978) (the "WKBJ method"). The BSR at near-normal incidence was matched by varying $V_{p}$, density, and thickness of the low-impedance layer (Fig. 9). Initial $V_{p}$ values at the interfaces of the low-impedance layer were those observed in the sonic log 
Figure 6. Sonic velocities and estimated densities are converted from depth to time and resampled at 4-ms intervals. These values are used to calculate the reflection coefficients shown in the center plot. The BSR is produced by the pair of negative and positive reflection coefficients just below $3.8 \mathrm{~s}$. Synthetic seismogram produced from convolution of the reflection coefficients with a source derived from seafloor returns near Site 860 .

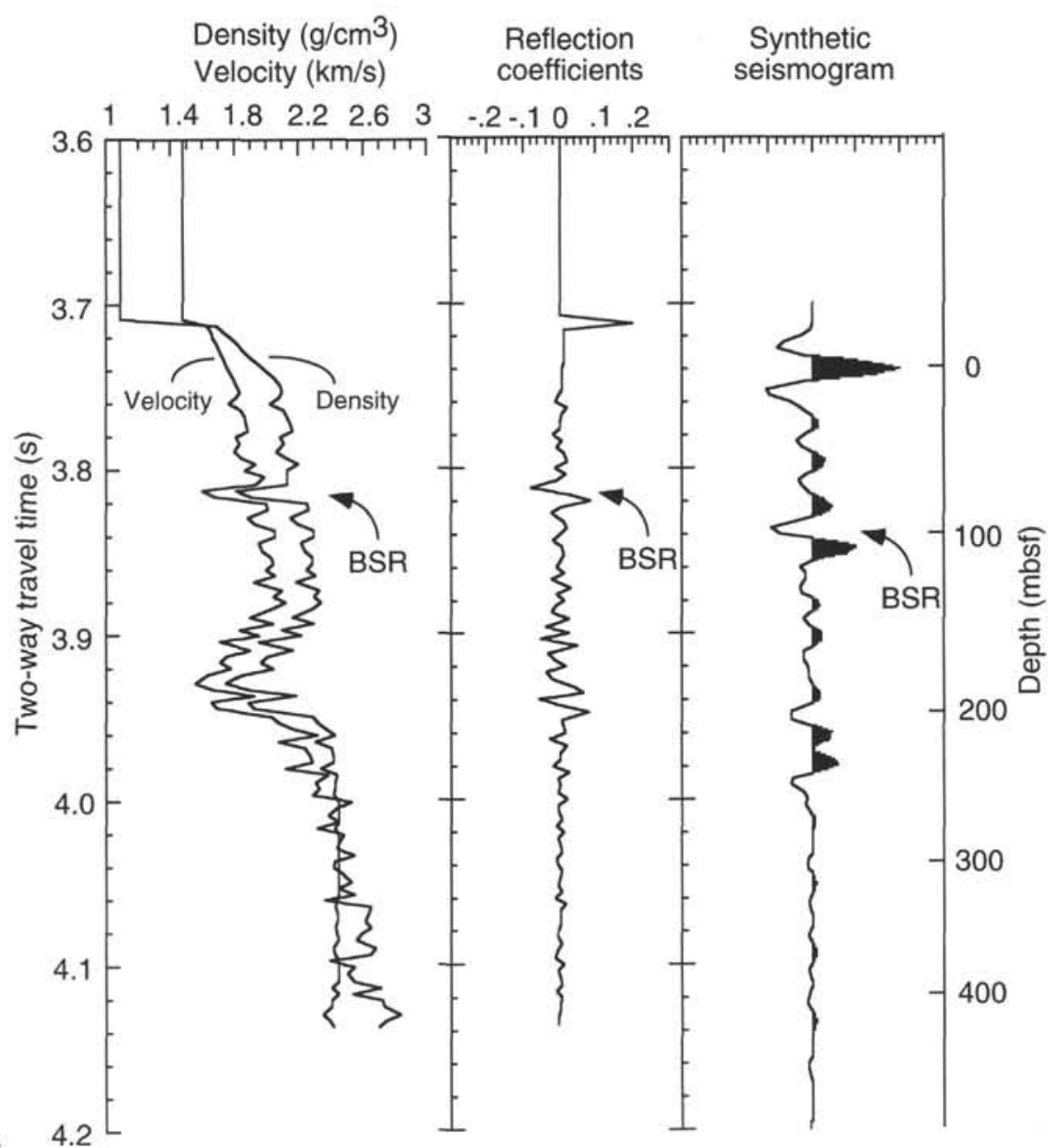

Site 859
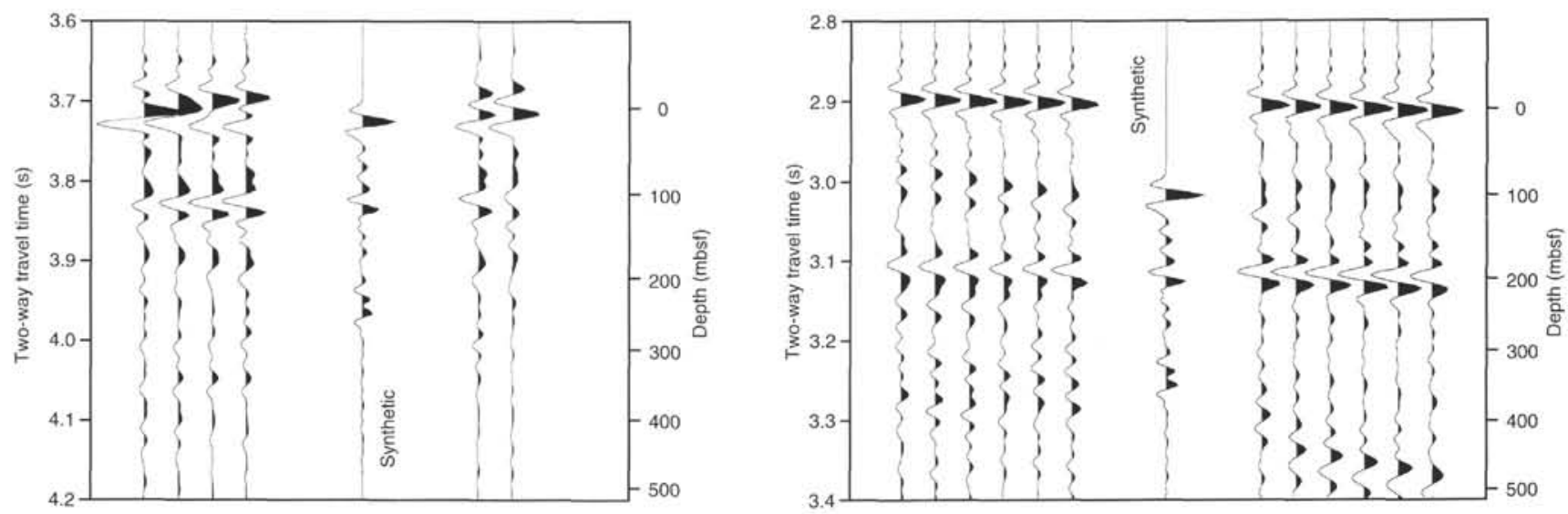

Figure 7. Comparison of the synthetic seismogram with the stacked seismic traces on both sides of Site 859. The waveform of the BSR matches the seismic data well. Amplitudes of both the seafloor and BSR events are affected by focusing due to seafloor topography. Synthetic seismogram of Figure 5 is compared with the BSR at Site 860. The seafloor here is relatively smooth, and the amplitudes of the seafloor and BSR are reasonably consistent laterally. The BSR here is nearly twice the depth below seafloor as at Site 859 , but the amplitudes and waveform of the BSR are close to that of the synthetic seismogram generated from the Site 859 sonic data.

from Site 859. Densities were estimated from $V_{p}$ as discussed above. The data are matched well with the $1 \%$-free-gas model (Fig. 9).

Figure 10 shows the AVO of the negative pulse of the BSR waveform at CDP 1389 (Fig. 9) as they compare with the amplitudes expected from the $1 \%$-free-gas and no-free-gas models. An important consideration is the source and streamer directivity caused by the finite length of the source and receiver arrays. Both of these corrections are relatively small for the data examined here because of the acquisition parameters. The directivity is largely dependent on group spacing and number of receivers for signals of equal frequency content (Sheriff and Geldart, 1982). Group spacing with the 240-channel streamer was small $(12.5 \mathrm{~m})$, and losses from streamer directivity are 
A

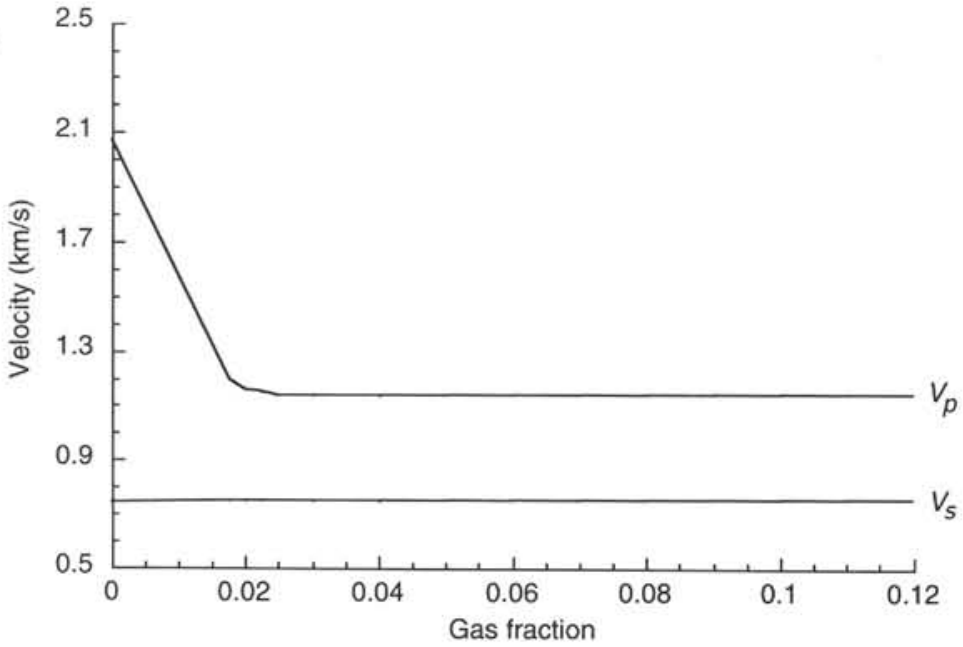

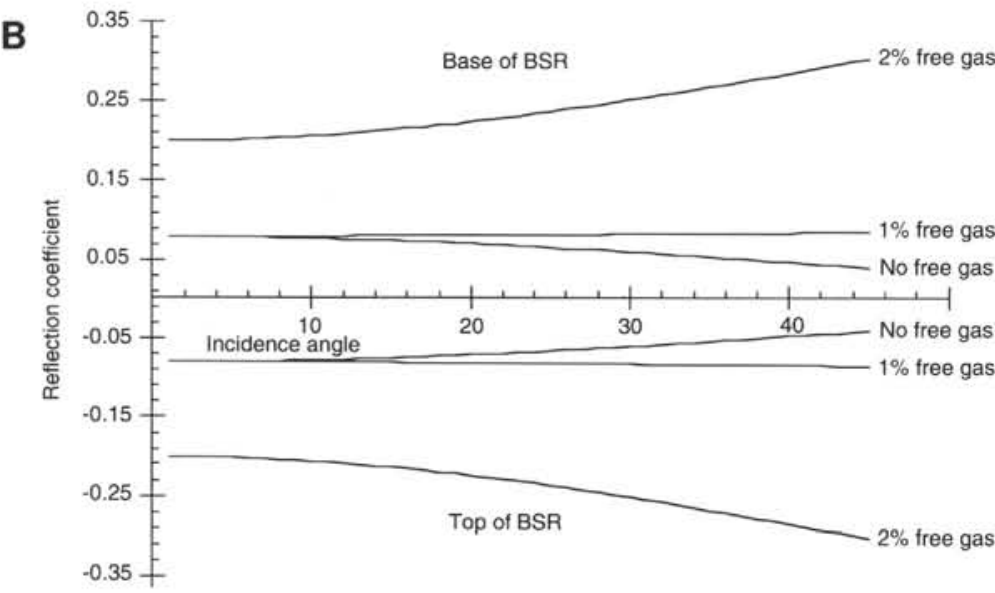

calculated to be less than $3 \%$ at the farthest offset $(3.0 \mathrm{~km})$. Source directivity is considerably harder to estimate, as it depends on gun sizes and bubble interactions. Estimates made here attribute losses to be slightly greater than streamer directivity, approximately $4 \%$, and total directivity loss is estimated to decrease signal amplitude at far offsets to $93 \%$ of near offset amplitudes. Amplitudes have been corrected for geometric spreading and directivity losses. Despite some noise in the amplitudes, probably due to the variation in hydrophone sensitivity and variation in reflectivity across the $25-\mathrm{m}$ bin, these values define a consistent trend that is shown by the smooth polynomial fit to the data. The seafloor reflection amplitude drops to $55 \%$, while the BSR amplitudes are nearly unchanged over the range of these offsets. For comparison the amplitudes predicted by the $1 \%$ free-gas model is shown in Figure 10A, and the no-free-gas model in Figure 10B.

The $1 \%$-free-gas model depicted in Figure 9 provides a good match to amplitudes of both the seafloor return and the BSR at all offsets as shown in Figure 10A. In the near offsets, the model requires a small positive impedance contrast just above the thin low-impedance layer. This produces the small positive portion of the waveform that precedes the large negative lobe, and is clearly absent in the model without this positive impedance boundary (Fig. 9). This probably corresponds to the velocity increase due to increased hydrate concentrations noted above, as the step is similar to the increase in velocity just above the BSR observed in the log at $88 \mathrm{mbsf}$. At the far offsets, amplitudes may be slightly lower than predicted by the $1 \%$-free-gas model, so this is probably an upper limit to the quantity of gas. With the no-gas model, the resulting amplitudes at $45^{\circ}$ incidence are only $75 \%$ of the observed amplitude (Fig. 10B).
Figure 8. A. Theoretical estimates of the changes in $V_{p}$ and $V_{s}$ with increasing gas concentrations predicted by Domenico (1976) using Biot theory of sound propagation in sediments. Large decreases in $V_{p}$ occur with gas concentrations up to $2 \%$ free gas. Shear-wave velocities are relatively unaffected at all gas concentrations. B. Reflection coefficients calculated for the top and bottom interfaces of a layer with amplitude comparable to that of the BSR. We compute cases for $2 \%, 1 \%$, and no free gas defined by the $V_{p}$ and $V_{s}$ properties of Figure $8 \mathrm{~A}$. Incidence angles of $45^{\circ}$ for the BSR are expected at offsets of $3.0 \mathrm{~km}$ for our seismic data.

\section{DISCUSSION}

The presence of free gas provides a good explanation of many of the observations made from the analyses of both the seismic data and sonic log data. The thin, low-velocity interval observed in the sonic log produces a reflection that matches the BSR seen in the seismic data on Line 745 . If the BSR were produced by the contrast in impedance between hydrate-bearing and hydrate-free sediments, then the reflection waveform characteristics should be those of a single reflective boundary produced at the transition. Modeling shows that the reflection is well matched with two closely spaced interfaces, and it is not matched nearly as well with a single interface.

Our estimates made here place the hydrate concentrations on the order of $10 \%$ in most of the hydrate stability zone, with somewhat higher concentrations, $18 \%$ of the pore space, along the base of the hydrate interval. The maximum hydrate concentration inferred from the pore-fluid chemistry is no more than $25 \%$ of pore space at intervals shallower than the logged interval. The reflection coefficients that produce the strong BSRs require concentrations considerably greater than observed if the hydrate is the sole cause of the impedance contrast. Estimates of the hydrate concentration, using the time average equation and with the parameters measured here, indicate that concentrations of hydrate must be at least $55 \%$ of the pore space (Fig. 11). This may be an overestimate because of cementation effects not accounted for here, but in any case, examination of the velocities in hydrate-bearing vs. hydrate-free sediments shows they generate only small impedance differences. Free gas is a better explanation of the BSR along Line 745 .

One of the best indications that gas is the cause of the BSR along Line 745 is the low velocities that were recorded within the thin layer 
A

CDP 1389

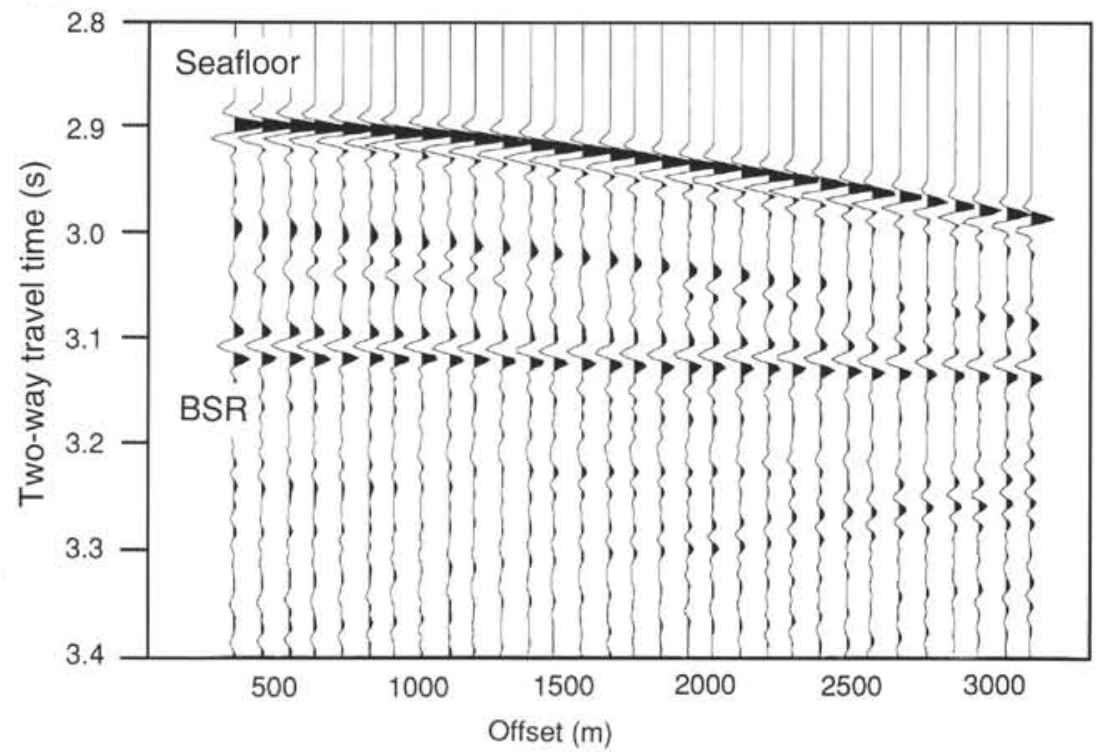

B Model CDP 1389

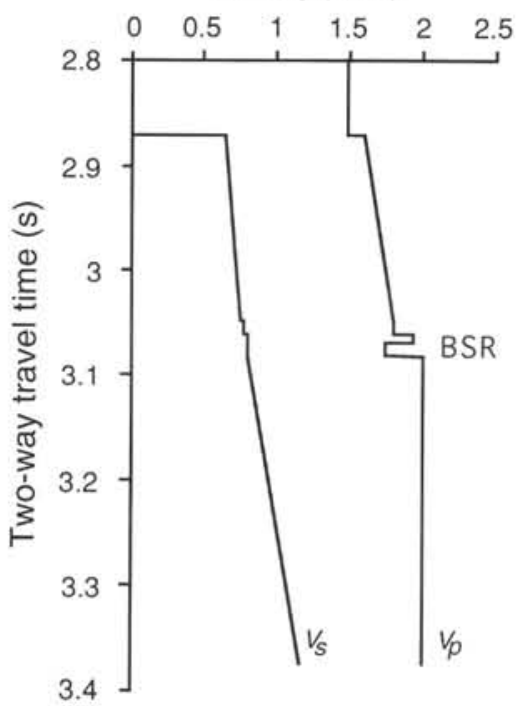

C

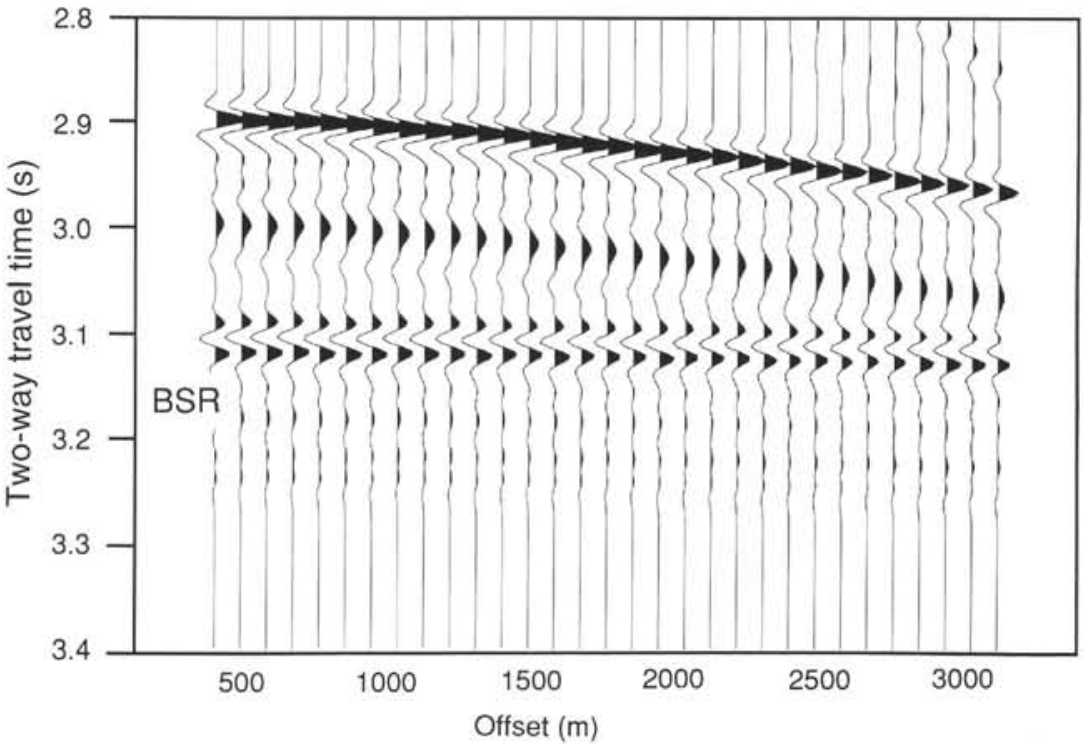

Figure 9. A. CDP 1389 acquired at Site 860 . Shown is every 8 th trace. B. Model of $V_{p}$ and $V_{s}$ for Site 860 that produces the seismogram shown in C. The $V_{p}$ values are based on those measured through the BSR at Site 859. The changes in $V_{p}$ that produce the BSR do not have corresponding $V_{s}$ changes. C. Model of traces from CDP 1389 produced with the WKBJ modeling technique. Amplitudes and waveforms of the seafloor and BSR match reasonably well in both near and far offsets. These amplitudes are shown in Figure 10.

at the base of the hydrate stability zone (Layer E, Fig. 3). The velocity is significantly lower at the BSR than the surrounding sediments, and is unusually low for their depth. If the BSR were produced from the physical property changes associated with hydrate-bearing sediment overlying hydrate-free sediment, velocities would be expected to be anomalously high in the hydrate-bearing sediment and then return to values typical of hydrate-free sediment at Site 859. Instead anomalously low velocities of $1.6 \mathrm{~km} / \mathrm{s}$ are observed in the sonic $\log$. The low velocity is particularly difficult to explain in normal sedimentary sections. While low-velocity intervals in sediments have been attributed to overpressured, underconsolidated intervals elsewhere, there are no indications of overpressures here. While overpressuring can occur in thin intervals along fault conduits (e.g., Bangs and Westbrook, 1991), it is not believed to be the case for the BSR.

The presence of gas as the cause of the reflection is substantiated by the AVO analysis. The amplitude differences between near and far offsets observed here are not as great as might be expected with large accumulations of gas, but are $125 \%$ greater than what is expected without the gas. What is also apparent from both the AVO and the velocities in the free-gas interval is that the quantity of gas is small, $\sim 1 \%$, otherwise if more gas were present $V_{p}$ would be lower and the AVO effect would be larger at far offsets. Furthermore, concentrations 

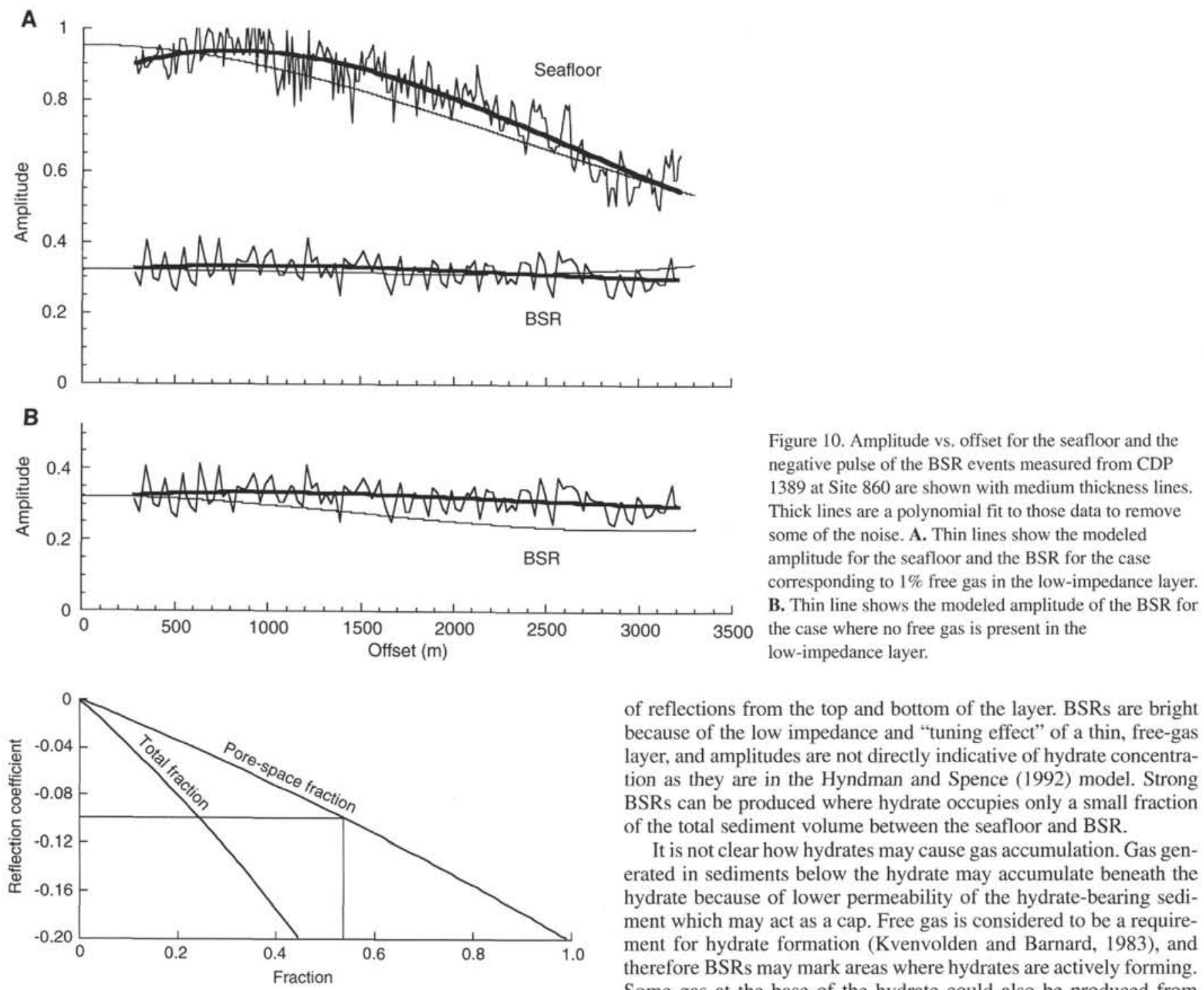

of reflections from the top and bottom of the layer. BSRs are bright because of the low impedance and "tuning effect" of a thin, free-gas layer, and amplitudes are not directly indicative of hydrate concentration as they are in the Hyndman and Spence (1992) model. Strong BSRs can be produced where hydrate occupies only a small fraction of the total sediment volume between the seafloor and BSR.

It is not clear how hydrates may cause gas accumulation. Gas generated in sediments below the hydrate may accumulate beneath the hydrate because of lower permeability of the hydrate-bearing sediment which may act as a cap. Free gas is considered to be a requirement for hydrate formation (Kvenvolden and Barnard, 1983), and therefore BSRs may mark areas where hydrates are actively forming. Some gas at the base of the hydrate could also be produced from hydrate dissociation where changes in pressure-temperature conditions shift the hydrate stability field. Accumulation of overburden above BSRs will cause the hydrate stability field to shift upward. In southern Chile the hydrate stability field will also shift upward with changes in pressure-temperature conditions associated with ridge subduction, which may also contribute to hydrate dissociation and the release of gas at the base of the hydrate stability field.

\section{CONCLUSIONS}

is observed. The sensitivity of $V$ in the $0-2 \%$ free-gas range and its effect on AVO make distinctions between small quantities possible.

The amplitude of the BSR is directly related to gas concentration and to the thickness of the layer. The largest amplitude BSRs on Line 745 are generated from small concentrations of no more than $1 \%$ free gas, which produces impedance contrasts at the top and bottom interfaces of the layer. The opposite reflection polarity at the layer interfaces and their separation of 7-12 m cause constructive interference and enhance the BSR amplitude. Intervals thicker than the dominant wavelength of the source $(\sim 25 \mathrm{~m})$ would produce two distinct reflections from the top and bottom of the free-gas layer. Two reflections are not characteristic of BSRs in southern Chile or other BSRs reported in the literature; thus, where there is a free-gas layer, the interval is typically $<\sim 25 \mathrm{~m}$ thick. If it is a single interface at other locations, it must have a sufficiently gradual transition at its base that no reflection is produced. Weaker BSRs are produced from either lower gas concentrations or layers thinner than $\sim 5 \mathrm{~m}$, which cause destructive interference

For the first time physical properties have been recorded in logs through the base of the hydrate stability field. Seismic modeling shows the properties recorded in the log closely reproduce the bottom-simulating reflection in its amplitude and waveform characteristics as it is observed in the seismic data that intersect these sites. A model constructed of the BSR based on properties recorded in the logs reproduces the phase-reversed reflection that characterizes BSR with a layer approximately $10 \mathrm{~m}$ thick, in which $P$-wave velocities decrease from values of approximately $1.95 \mathrm{~km} / \mathrm{s}$ above and below the layer to $1.6-1.7 \mathrm{~km} / \mathrm{s}$ within the layer. Models also show that the slight increase in amplitude with offset observed in the BSR can be matched when shear-wave velocities remain nearly constant above, within, and below the layer. This model of the AVO corresponds well with theoretical and laboratory estimates of $V_{p}$ and $V_{s}$ in sediments with small quantities of free gas, approximately $1 \%$. 
Two intervals in the hydrate stability zone have relatively higher velocities that are interpreted as intervals enriched with hydrate. Estimates of the quantity of hydrate based on the log velocities are between $10 \%$ and $18 \%$ of the pore space. These quantities are too small to generate an impedance contrast as large as the BSRs along Line 745, and free gas is a more reasonable explanation for the BSR in the vicinity of Leg 141 drill sites than a transition to hydrate-free sediments.

The high amplitude of the BSR relative to other reflections within and below the hydrate layer, and the lack of other low-velocity intervals in the log, indicate that the BSR interval is a relatively enriched interval of free gas. Some of the gas that generates the BSR may be produced by dissociation of hydrate following the upward migration of the hydrate stability field in response to the active thermal and tectonic activity associated with spreading-ridge subduction at the Chile triple junction.

\section{ACKNOWLEDGMENTS}

We thank Tom Shipley and Warren Wood for their thoughtful comments on an earlier draft. Reviews by John Miller and Roy Hyndman were also greatly appreciated. Support for this work came from grants JOI 9-91, USSSP 14120672, and USSSP 14120676. UTIG contribution number 1102.

\section{REFERENCES}

Bangs, N., Cande, S.C., Lewis, S.D., and Miller, J., 1992. Structural framework of the Chile Margin at the Chile Ridge collision zone. In Behrmann, J.H., Lewis, S.D., Musgrave, R.J., et al., Proc. ODP, Init. Repts., 141: College Station, TX (Ocean Drilling Program), 11-21.

Bangs, N.L., and Westbrook, G.K., 1991. Seismic modeling of the décollement zone at the base of the Barbados Ridge accretionary complex. J. Geophys. Res., 96:3853-3866.

Behrmann, J.H., Lewis, S.D., Musgrave, R.J., et al., 1992. Proc. ODP, Init. Repts., 141: College Station, TX (Ocean Drilling Program).

Bryan, G.M., 1974. In situ indication of gas hydrate. In Kaplan, I.R. (Ed.), Natural Gases in Marine Sediments: New York (Plenum), 299-308.

Cande, S.C., Leslie, R.B., Parra, J.C., and Hobart, M.. 1987. Interaction between the Chile Ridge and Chile Trench: geophysical and geothermal evidence. J. Geophys. Res., 92:495-520.

Chapman, C.H., 1978. A new method for computing synthetic seismograms. Geophys. J. R. Astron. Soc., 54:481-518.

Collins, B.P., and Watkins, J.S., 1985. Analysis of a gas hydrate off Mexico using seismic processing techniques and Deep Sea Drilling Project Leg 66 results. Geophysics, 50:16-24.

Dillon, W.P., and Paull, C.K. 1983. Marine gas hydrates-II. Geophysical evidence. In Cox, J.L. (Ed.), Natural Gas Hydrates: Properties, Occurrences, and Recovery: London (Butterworths), 73-90.

Domenico, S.N., 1976. Effect of brine-gas mixture on velocity in an unconsolidated sand reservoir. Geophysics, 41:882-894.

1977. Elastic properties of unconsolidated porous sand reservoirs. Geophysics, 42:1339-1368.

Gassmann, F., 1951. Elasticity of porous media. Vierteljahrsschr. Naturforsch. Gesellschaft Zurich, 96:1-22.

Gregory, A.R., 1976. Fluid saturation effects on dynamic elastic properties of sedimentary rocks. Geophysics, 41:895-921.

Hamilton, E.L., 1978. Sound velocity-density in sea-floor sediments and rocks. J. Acoust. Soc. Am., 66:366-377.

1979. $V_{p} / V_{\text {s }}$ and Poisson's ratios in marine sediments and rocks. $J$. Acoust. Soc. Am., 66:1093-1101.

Hyndman, R.D., and Davis, E.E., 1992. A mechanism for the formation of methane hydrate and seafloor bottom-simulating reflectors by vertical fluid expulsion. J. Geophys. Res., 97:7025-7041.

Hyndman, R.D., and Spence, G.D., 1992. A seismic study of methane hydrate marine bottom simulating reflectors. J. Geophys. Res., 97:6683-6698.

Kvenvolden, K.A., and Barnard, L.A., 1983. Hydrates of natural gas in continental margins. In Watkins, J.S., and Drake, C.L. (Eds.), Studies in Continental Margin Geology: AAPG Mem., 34:631-640.
Kvenvolden, K.A., and Kastner, M., 1990. Gas hydrates of the Peruvian outer continental margin. In Suess, E., von Huene, R., et al., Proc. ODP, Sci. Results, 112: College Station, TX (Ocean Drilling Program), 517-526.

Kvenvolden, K.A., and McMenamin, M.A., 1980. Hydrates of natural gas: a review of their geologic occurrence. Geol. Surv. Circ. (U.S.), 825.

Macleod, M.K., 1982. Gas hydrates in ocean bottom sediments. AAPG Bull., 66:2649-2662.

Markl, R.G., Bryan, G.M., and Ewing, J.I., 1970. Structure of the BlakeBahama outer ridge. J. Geophys. Res., 75:4539-4555.

Mathews, M.A., and von Huene, R., 1985. Site 570 methane hydrate zone. In von Huene, R., Aubouin, J., et al., Init. Repts. DSDP, 84: Washington (U.S. Govt. Printing Office), 773-790.

McKay, M.E., Jarrard, R.D., Westbrook, G.K., Hyndman, R.D., and Shipboard Scientific Party of Ocean Drilling Program Leg 146, 1994. Origin of bottom-simulation reflectors: geophysical evidence from the Cascadia accretionary prism. Geology, 22:459-462.

Miller, J.J., Lee, M.W., and von Huene, R., 1991. A quantitative analysis of gas hydrate phase boundary reflection (BSR), offshore Peru. AAPG Bull., 75:910-924.

Minshull, T., and White, R., 1989. Sediment compaction and fluid migration in the Makran accretionary prism. J. Geophys. Res., 94:7387-7402.

Murphy, W.F., 1984. Acoustic measures of partial gas saturation in tight sandstones. J. Geophys. Res., 89:11549-11559.

Ostrander, W.J., 1984. Plane-wave reflection coefficients for gas sands at non-normal angles of incidence. Geophysics, 49:1637-1648.

Pearson, C., Murphy, J., and Hermes, R., 1986. Acoustic resistivity measurements on rock samples containing tetrahydrofuran hydrates: laboratory analogies to natural gas hydrate deposits. J. Geophys. Res., 91:14132-14138.

Sheridan, R.E., Gradstein, F.M., Barnard, L.A., et al., 1982. Early history of the Atlantic Ocean and gas hydrates on the Blake Outer Ridge-results of the Deep Sea Drilling Project Leg 76. Geol. Soc. Am. Bull., 93:876-885.

Sheriff, R.E., and Geldart, L.P., 1982. Exploration Seismology (Vol. 1): History, Theory, and Data Acquisition: New York (Cambridge Univ. Press).

Shipley, T.H., and Didyk, B.M., 1982. Occurrence of methane hydrates offshore southern Mexico. In Watkins, J.S., Moore, J.C., et al., Init. Repts. DSDP, 66: Washington (U.S. Govt. Printing Office), 547-555.

Shipley, T.H., Houston, M.H., Buffler, R.T., Shaub, F.J., McMillen, K.J., Ladd, J.W., and Worzel, J.L., 1979. Seismic evidence for widespread possible gas hydrate horizons on continental slopes and rises. AAPG Bull., 63:2204-2213.

Shuey, R.T., 1985. A simplification of the Zoeppritz equations. Geophysics, 50:609-614.

Sloan, E.D., 1990. Clathrate Hydrates of Natural Gasses: New York (Marcel Dekker).

Stoll, R.D., and Bryan, G.M., 1979. Physical properties of sediments containing gas hydrates. J. Geophys. Res., 84:1629-1634.

Tucholke, B.E., Bryan, G.M., and Ewing, J.I., 1977. Gas-hydrate horizons detected in seismic-profiler data from the western North Atlantic. AAPG Bull., 61:698-707.

Warner, M., 1990. Absolute reflection coefficients from deep seismic reflections. Tectonophysics, 173:15-23.

Whalley, E., 1980. Speed of longitudinal sound in clathrate hydrates. $J$. Geophys. Res., 85:2539-2542.

White, R.S., 1979. Gas hydrate layers trapping free gas in the Gulf of Oman. Earth Planet. Sci. Lett., 42:114-120.

Widess, M.B., 1973. How thin is a thin bed? Geophysics, 38:1176-1180.

Worthington, P.F., 1975. Quantitative geophysical investigation of granular aquifers. Geophys.-Surv., 2:313-366.

Wyllie, M.R.J., Gregory, A.R., and Gardner, L.W., 1956. Elastic wave velocities in heterogeneous and porous media. Geophysics, 21:41-70.

\footnotetext{
"Abbreviations for names of organizations and publications in ODP reference lists follow the style given in Chemical Abstracts Service Source Index (published by American Chemical Society).
}

Date of initial receipt: 19 July 1993

Date of acceptance: 4 October 1994

Ms 141SR-026 